\title{
Performance and Emissions of an Ammonia-Fueled SI Engine with Hydrogen Enrichment
}

\author{
Charles LHUILLIER, Pierre BREQUIGNY, Francesco CONTINO, Christine ROUSSELLE
}

\begin{abstract}
While the optimization of the internal combustion engine (ICE) remains a very important topic, alternative fuels are also expected to play a significant role in the reduction of $\mathrm{CO}_{2}$ emissions. High energy densities and handling ease are their main advantages amongst other energy carriers. Ammonia $\left(\mathrm{NH}_{3}\right)$ additionally contains no carbon and has a worldwide existing transport and storage infrastructure. It could be produced directly from renewable electricity, water and air, and is thus currently considered as a smart energy carrier and combustion fuel. However, ammonia presents a low combustion intensity and the risk of elevated nitrogen-based emissions, thus rendering in-depth investigation of its suitability as an ICE fuel necessary.
\end{abstract}

In the present study, a recent single-cylinder spark-ignition engine is fueled with gaseous ammonia/hydrogen/air mixtures at various hydrogen fractions, equivalence ratios and intake pressures. A small hydrogen fraction is used as combustion promoter and might be generated in-situ through $\mathrm{NH}_{3}$ catalytic or heat-assisted dissociation. The in-cylinder pressure and exhaust concentrations of selected species are recorded and analyzed. Results show that ammonia is a very suitable fuel for SI engine operation, since high power outputs could be achieved with indicated efficiencies higher than $37 \%$ by taking advantage of the promoting effects of supercharging and hydrogen enrichment around $10 \%$ by volume. High NOx and unburned $\mathrm{NH}_{3}$ exhaust concentrations were also observed under fuellean and fuel-rich conditions, respectively. While hydrogen enrichment promotes the $\mathrm{NH}_{3}$ combustion efficiency and helps reducing its exhaust concentration, it has a promoting effect on NOx formation, assumedly due to higher flame temperatures. Therefore, it is recommended to take advantage of the simultaneous presence of exhaust heat, $\mathrm{NOx}$ and $\mathrm{NH}_{3}$ in a dedicated after-treatment device to ensure the economic and environmental viability of future ammoniafueled engine systems.

\section{Introduction}

The objectives of the Paris Agreement [1] aiming at mitigating climate change imply a global transition from fossil to renewable resources use in the next decades. Today's main energy sources, such as fossil fuels should be replaced by renewable energy sources, accompanied by an increased electrification of many usages. Alternative fuels are widely considered as important energy carriers in that context, since they are particularly suited for specific hard-toelectrify end-uses, such as high temperature heat and other industrial needs or long-distance mobility, as well as for mid- and long-term energy storage.

Ammonia $\left(\mathrm{NH}_{3}\right)$ is currently receiving an increased interest from industry and academia as a potential renewable carbon-free energy carrier [2]. It is both considered as an efficient hydrogen carrier with $17.8 \%$ hydrogen content by mass and as a direct fuel for combustion or fuel cell application. Even though ammonia use as an internal combustion engine fuel has been considered since many decades, its deployment was first hindered by the competition with hydrocarbon fuels in terms of availability, handling ease and safety, energy density and combustion properties. Indeed, it is a toxic chemical that exhibits a difficult flammability and very low combustion intensity, illustrated by its narrow flammability limits (FL) and low Laminar Burning Velocity (LBV) in Table 1, respectively. However, today's new paradigm is making fossil hydrocarbons obsolete due to their unacceptable environmental impact, and ammonia presents many advantages as an alternative. As illustrated in Table 1, ammonia can be stored in liquid form at ambient temperature under mild pressure conditions, thus ensuring a comparable energy density with other fuels, owing to its competitive Lower Heating Value (LHV). Its high octane rating is a beneficial feature for its use in boosted SparkIgnition (SI) engines, and its cooling properties may represent a significant opportunity for efficiency improvement when used as a transportation fuel [3]. Since it could soon be produced economically directly from water, air and renewable energy sources, and since its combustion releases no carbon dioxide, a life cycle analysis by Bicer and Dincer [4] showed that greenhouse gas emissions could be reduced by almost a factor three by using ammonia-fueled vehicles instead of gasoline vehicles.

Table 1. Ammonia properties and comparison with other fuels at $300 \mathrm{~K}$ and 0.1 MPa, unless stated otherwise. Data from [5-7].

\begin{tabular}{|l|l|l|l|l|l|}
\hline Species & Ammonia & Methanol & Hydrogen & Methane & Gasoline \\
\hline Formula & $\mathrm{NH}_{3}$ & $\mathrm{CH}_{3} \mathrm{OH}$ & $\mathrm{H}_{2}$ & $\mathrm{CH}_{4}$ & - \\
\hline Storage & Liquid & Liquid & Compressed & Compressed & Liquid \\
\hline $\begin{array}{l}\text { Storage } \\
\text { temperature (K) }\end{array}$ & 300 & 300 & 300 & 300 & 300 \\
\hline $\begin{array}{l}\text { Storage pressure } \\
(\mathrm{MPa})\end{array}$ & 1.1 & 0.1 & 70 & 25 & 0.1 \\
\hline $\begin{array}{l}\rho @ \text { storage } \\
\left.\text { conditions (kg.m }{ }^{-3}\right)\end{array}$ & 600 & 784.6 & 39.1 & 187 & $\sim 740$ \\
\hline LHV (MJ/kg) & 18.8 & 19.9 & 120 & 50 & 44.5 \\
\hline $\begin{array}{l}\text { LBV @ } \phi=1 \\
\left(\mathrm{~m} . \mathrm{s}^{-1}\right)\end{array}$ & 0.07 & 0.36 & 3.51 & 0.38 & 0.58 \\
\hline $\begin{array}{l}\text { Auto-ignition } \\
\text { temperature (K) }\end{array}$ & 930 & 712 & $773-850$ & 859 & 503 \\
\hline $\begin{array}{l}\text { Research Octane } \\
\text { Number }\end{array}$ & 130 & 119 & $>100$ & 120 & $90-98$ \\
\hline FL in air (vol.\%) & $15-28$ & $6.7-36$ & $4.7-75$ & $5-15$ & $0.6-8$ \\
\hline
\end{tabular}

Early studies (1960's) considered ammonia as an ICE fuel for military applications in case of hydrocarbon fuels shortage. Even though its use in compression-ignition (CI) engines was investigated [8], SI engines were found to be the best configuration. Cornelius et al. [9] successfully ran single-cylinder and multi-cylinder SI engines fueled with neat ammonia and reported poor engine performance under normally loaded conditions and a compression ratio (CR) of around 10:1 as compared to gasoline operation. For instance, the single-cylinder engine had an indicated efficiency of about $22 \%$ at full load, $1200 \mathrm{rpm}$ and CR =9.4:1. Similarly, important power penalties were observed, as well as very high exhaust $\mathrm{NH}_{3}$ emissions. Thus, the authors used several strategies to improve the performance and reduce the emissions, including supercharged operation, increased $\mathrm{CR}$ and hydrogen blending in the $\mathrm{NH}_{3}$ fuel. The performance greatly improved by using a combination of these strategies and was very close to the performance under gasoline 
operation, while $\mathrm{NH}_{3}$ emissions dropped significantly as well. The optimal $\mathrm{H}_{2}$ fraction to be added to the fuel was found to be about $2 \%$ by mass of fuel, which is about $15 \%$ by volume. Intake hydrogen was produced by $\mathrm{NH}_{3}$ dissociation using a dedicated device, leading to an inevitable volumetric efficiency penalty, due to the stoichiometry of the dissociation reaction. NOx emissions were found to be comparable with the ones under gasoline operation, but increased as the indicated efficiency increased. NOx emissions where further investigated by Sawyer et al. [10]. Furthermore, Cornelius et al reported $\mathrm{H}_{2}$ exhaust emissions under fuel-rich conditions even for neat $\mathrm{NH}_{3}$ fuel, indicating $\mathrm{NH}_{3}$ dissociation in the cylinder. Starkman et al. [11] carried out a similar investigation on a CFR (Collaborative Fuel Research) SI engine, and concluded that the performance of gasoline operation could be closely reached with ammonia, provided that the spark timing is advanced correctly and that a minimum amount of hydrogen in present in the fuel. The minimum value of $4-$ $5 \%$ by mass is reported at $1800 \mathrm{rpm}$ and $\mathrm{CR}=8: 1$. Increasing the compression ratio and the cylinder wall temperatures are also shown as beneficial for the power output, and direct injection of liquid $\mathrm{NH}_{3}$ is suggested as a further improvement regarding the volumetric efficiency. However, the indicated efficiency and the specific fuel consumption were still found worse than for gasoline operation, probably explaining that ammonia did not become a popular ICE fuel at that time.

Nowadays, several research groups are carrying investigations to assess the best methods to compensate ammonia's poor combustion properties, as summarized recently by Valera-Medina et al. [7]. A wide variety of technical applications and conditions are tested, including compression- and spark-ignition ICEs, as well as gas turbines (GT), with direct or indirect ammonia injection as a single or dual fuel in gaseous or liquid phase. The dual fuel approach was widely studied experimentally in CI engines, using kerosene, diesel, dimethyl-ether or hydrogen from ammonia dissociation as a pilot fuel to promote the auto-ignition [12-17].

Aiming at using $\mathrm{NH}_{3}$ as a main fuel for further decarbonization, and in order to take advantage of its high octane rating, the spark-ignition is seen as a meaningful method to initiate the combustion in ICEs. Granell et al. $[18,19]$ fueled a CFR engine with ammonia and gasoline/air premixture. A $70 \% \mathrm{NH}_{3} / 30 \%$ gasoline blend by energy was given as a good tradeoff at full load, while neat gasoline is required at idle. The authors suggested to use supercharged operation instead of increasing the CR for the given chamber geometry, since $\mathrm{NH}_{3}$ requires an early SI timing. Engine-out $\mathrm{NH}_{3}$ emissions were mostly proportional to the intake $\mathrm{NH}_{3}$ concentration and reached 22000 ppmvw for a stoichiometric $\mathrm{NH}_{3} /$ air mixture at the recommended 10:1 CR. HC and CO emissions decreased as a function of the $\mathrm{NH}_{3}$ amount, as well as NOx emissions (slightly) around 2500 ppmvw. Ryu et al. [20] tested direct gaseous $\mathrm{NH}_{3}$ injection with gasoline in a CFR engine $(\mathrm{CR}=10: 1)$. The range for acceptable injection pressure allowing overcoming in-cylinder pressure while avoiding $\mathrm{NH}_{3}$ liquefaction is narrow, because of its low vaporization pressure. The best power output was achieved for advanced $\mathrm{NH}_{3}$ injection timing and increased injection duration. The brake specific energy consumption (BSEC) was unchanged with ammonia addition, regardless of the load. $\mathrm{NOx}$ and $\mathrm{NH}_{3}$ emissions increased strongly with the intake $\mathrm{NH}_{3}$ amount and the load. Those authors also suggested to partially dissociate ammonia in $\mathrm{H}_{2}$ and $\mathrm{N}_{2}$ prior to direct injection with gasoline and air in the same CFR engine [21]. With partial dissociation, the combustion efficiency was significantly increased and the BSEC and the nitrogen-based emissions were reduced accordingly, especially at low loads.

Ammonia combustion enhancement by in-situ $\mathrm{NH}_{3}$ dissociation was also investigated by Frigo et al. [22-24] not in a CFR but in a commercial two-cylinder SI engine $(\mathrm{CR}=10.7: 1)$ equipped with a dedicated catalytic reformer. The stability of the whole system was proven for stoichiometric mixtures over a range of engine speeds and loads. A minimum hydrogen-to-ammonia energy ratio of $7 \%$ at full load and $11 \%$ at half load was injected, and could be achieved when operating the reformer. They suggested increasing the CR or settingup a tailored ignition system for cold start. NOx emissions were found to be quite low with a maximum around $1700 \mathrm{ppm}$ at full load and $3000 \mathrm{rpm}$. In [25], the same authors reported $\mathrm{NH}_{3}$ emissions surprisingly under $100 \mathrm{ppm}$. Mørch et al. [6] similarly studied $\mathrm{NH}_{3} / \mathrm{H}_{2}$ blends fueled in a SI engine (CFR) at various CR with $\mathrm{NH}_{3}$ provided from in-situ heat-assisted desorption from a metal ammine complex. They reported an increased efficiency compared with gasoline operation due to the possibility of knock-free CR increase. The best performance was found at stoichiometry for $10 \mathrm{vol} . \% \mathrm{H}_{2}$ in the fuel, since higher hydrogen fractions certainly induce higher wall heat losses. At this operating point, the authors recommended the use of Selective Catalytic Reduction (SCR) to eliminate the significant NOx exhaust fraction (1500 ppm), similar to the one observed for gasoline operation. This could be done conveniently, since ammonia is available in-situ. A focus on nitrogen-based pollutant emissions from a 80 vol. \% $\mathrm{NH}_{3} / 20$ vol. $\% \mathrm{H}_{2}$ fueled CFR engine was proposed by Westlye et al. [26]. In that study, NO emissions showed a leaner peak than for gasoline, but with similar magnitude. Higher $\mathrm{NO}_{2}$ emissions than with gasoline were reported but accounting for a low share around $3-4 \%$ of the total $\mathrm{NOx}$. $\mathrm{N}_{2} \mathrm{O}$ emissions due to flame temperatures below $1400 \mathrm{~K}$ were sufficiently low at maximum brake torque (MBT). Reduced NOx emissions could thus be achieved near stoichiometric conditions. $\mathrm{NH}_{3}$ slip of several hundreds of $\mathrm{ppm}$ is observed in the exhaust and tentatively explained by a rapid hydrogen flame propagation followed by a bulk combustion, while some ammonia is trapped in the piston crevices and cannot fully burn. Higher $\mathrm{CR}$ causes the increase of both $\mathrm{NOx}$ and $\mathrm{NH}_{3}$ emissions. Westlye et al. also demonstrated the feasibility of SCR systems as a function of the exhaust temperature and $\mathrm{NOx}$ to $\mathrm{NH}_{3}$ ratio.

Therefore, a strong evidence of the suitability of ammonia as a lowcarbon SI engine fuel is reported in the literature. In order to consolidate and actualize those findings and transpose them in recent SI engine designs, the present work introduces measurements of an ongoing systematic experimental study on premixed $\mathrm{NH}_{3} / \mathrm{H}_{2} /$ air combustion in a PSA four-valves GDI engine. As it has been shown that performance improvements could be obtained in supercharged operation with small amounts of $\mathrm{H}_{2}$ in the intake mixture, those conditions are the focus of this study. Following the idea of ammonia dissociation previous to injection as the hydrogen source, the focus should also be set on minimizing the necessary hydrogen content, so as to minimize the volumetric efficiency penalty induced by the higher volume of the dissociated gases. Thus, only very small $\mathrm{H}_{2}$ fractions are investigated here. In the first part, the experimental setup is introduced. New measurement data from engine experiments in a commercial engine are then presented and discussed. The influence of the hydrogen fuel fraction, the fuel/air equivalence ratio and the engine load on the engine performance, pollutant emissions and combustion efficiency is investigated.

\section{Experimental Method}

\section{Experimental Setup}

Engine experiments are conducted in a modern four-cylinder fourstroke SI engine modified to become a single-cylinder engine by fueling only one out of four cylinders. Table 2 presents the engine specifications. Even though the reactants are premixed and injected in the gaseous phase in the present work, that engine was optimized for gasoline direct injection. This means that the geometry of the piston bowl and of the pent-roof chamber provides improved aerodynamics when compared to more basic geometries as found in the CFR engine.

Table 2. Engine specifications. 


\begin{tabular}{|l|l|}
\hline Model & PSA EP6DT \\
\hline Displaced volume & $399.5 \mathrm{~cm}^{3}$ \\
\hline Stroke & $85.8 \mathrm{~mm}$ \\
\hline Bore & $77 \mathrm{~mm}$ \\
\hline Connecting rod length & $138.5 \mathrm{~mm}$ \\
\hline Compression ratio & $10.5: 1$ \\
\hline Number of valves & 4 \\
\hline
\end{tabular}

\begin{tabular}{|l|l|}
\hline $\mathrm{H}_{2} \mathrm{O}$ & $3950-4240$ \\
\hline $\mathrm{N}_{2} \mathrm{O}$ & $2000-2250$ \\
\hline $\mathrm{NO}$ & $1840-2080$ \\
\hline $\mathrm{NO}_{2}$ & $1250-1720$ \\
\hline $\mathrm{NH}_{3}$ & $1000-1240$ \\
\hline
\end{tabular}

The engine is driven by an electric motor at a fixed engine speed of $1500 \mathrm{rpm}$. The main shaft is equipped with a Kübler optical encoder for angular position monitoring with a 0.1 Crank Angle Degree (CAD) resolution. A water-cooled AVL piezoelectric pressure transducer with a $0.1 \mathrm{CAD}$ resolution provides in-cylinder pressure measurements. Its measuring range is $0-25 \mathrm{MPa}$. Engine intake and exhaust temperature and pressure are monitored using type $\mathrm{K}$ thermocouples and piezo-resistive absolute pressure transducers. The absolute cylinder pressure is obtained by equalizing the in-cylinder pressure and the mean absolute intake pressure $\left(P_{i n}\right) 20 \mathrm{CAD}$ after inlet valve opening. The spark plug used is the original one with a coil charging time set to $2 \mathrm{~ms}$. Ammonia, hydrogen and air gaseous flows are measured and controlled using Brooks thermal mass flowmeters with $\pm 0.7 \%$ accuracy, preheated to the intake temperature of $323 \mathrm{~K}$ and premixed in an intake plenum prior to injection. A scheme of the experimental setup is shown in Figure 1.

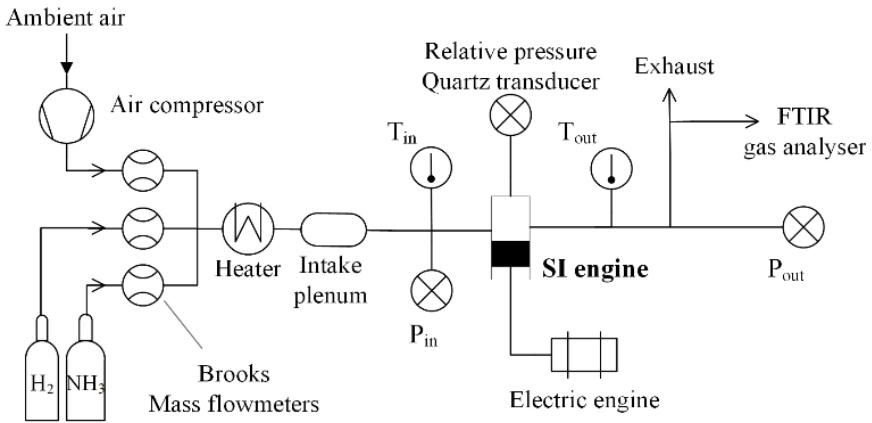

Figure 1. Layout of the experimental setup.

The wet exhaust gases are analyzed using a Gasmet Fourier Transform Infrared (FTIR) spectrometer to assess $\mathrm{H}_{2} \mathrm{O}$, NOx and $\mathrm{NH}_{3}$ concentrations. This equipment allows simultaneous quantitative measurement of many gaseous species with a good time resolution and accuracy, if the interferences between the species of interest are correctly identified and taken into account in the analysis settings. This has been done in the present work and the analysis ranges are presented in Table 3 for the different species. However, water vapor is a major interfering compound in infrared wavelengths, and its presence in the exhaust sample is inevitable due to the interest in measuring $\mathrm{H}_{2} \mathrm{O}$ itself and $\mathrm{NH}_{3}$, that would otherwise condensate along with $\mathrm{H}_{2} \mathrm{O}$. Even though its presence is accounted for in the interferences corrections, the authors believe that it may lead to some uncertainties in the exhaust gas measurements, in addition with other cross-component interferences. After preliminary verifications, the authors estimated a maximum uncertainty on the species concentrations of about $10 \%$ of the full scale, which is believed to be a very conservative value. Please note that error bars are not plotted consistently in order to improve readability.

Table 3. Analysis ranges for the FTIR species measurement.

\begin{tabular}{|l|l|}
\hline Species & Wave number range $\left(\mathrm{cm}^{-1}\right)$ \\
\hline
\end{tabular}

In addition, an ADEV gas analyzer is used on a dry exhaust gas sample for $\mathrm{H}_{2}$ (thermal conductivity) and $\mathrm{O}_{2}$ (paramagnetic) measurement. The water vapor measurement done with the FTIR analyzer is used for wet correction. The accuracy of the $\mathrm{H}_{2}$ and $\mathrm{O}_{2}$ analyzers is $\pm 1 \%$ (range $0-20 \% \mathrm{H}_{2}, 0-21 \% \mathrm{O}_{2}$ ).

\section{Operating conditions}

The global stoichiometric reaction of $\mathrm{NH}_{3} / \mathrm{H}_{2} /$ air combustion is as:

$$
\begin{gathered}
\left(1-x_{\mathrm{H}_{2}}\right) \mathrm{NH}_{3}+x_{\mathrm{H}_{2}} \mathrm{H}_{2}+\frac{3-x_{\mathrm{H}_{2}}}{4}\left(\mathrm{O}_{2}+3.76 \mathrm{~N}_{2}\right) \rightarrow \cdots \\
\left(\frac{3-x_{\mathrm{H}_{2}}}{2}\right) \mathrm{H}_{2} \mathrm{O}+\left(\frac{1-x_{\mathrm{H}_{2}}}{2}+3.76 * \frac{3-x_{\mathrm{H}_{2}}}{4}\right) \mathrm{N}_{2}
\end{gathered}
$$

where $x_{\mathrm{H}_{2}}$ is the hydrogen molar fraction in the fuel mixture. Nonstoichiometric mixtures are defined by the global fuel-air equivalence ratio:

$$
\phi=\frac{\frac{X_{\mathrm{H}_{2}}+X_{\mathrm{NH}_{3}}}{X_{\mathrm{air}}}}{\left(\frac{X_{\mathrm{H}_{2}}+X_{\mathrm{NH}_{3}}}{X_{\mathrm{air}}}\right)_{\mathrm{st}}}
$$

$X_{\mathrm{s}}$ represents the molar fraction of the species $\mathrm{s}$ in the reactive mixture. The stoichiometric air/fuel ratio by mass is around 6 for neat $\mathrm{NH}_{3}$ fuel and thus about twice smaller than for gasoline. The engine is operated at a fixed speed and fueled with near stoichiometric, slightly hydrogen-enriched ammonia/air gaseous mixtures. The intake temperature is kept constant for practical reasons but the intake pressure is varied, in order to simulate various engine loads. The spark-ignition timing is set at maximum brake torque (MBT) to ensure the maximum net indicated mean effective pressure $\left(I M E P_{\mathrm{n}}\right)$, a quantification of the work provided by the combustion in the absence of direct torque measurements. The friction losses caused by the three deactivated pistons make the latter irrelevant. Cycle-tocycle variability is considered by recording 100 consecutive pressure cycles for each test. Averaged values over 100 cycles are presented in this paper. Satisfactory cyclic stability is considered when the coefficient of variation of the $I M E P_{\mathrm{n}}$ over 100 cycles, $\operatorname{COV}\left(I M E P_{\mathrm{n}}\right)$, does not exceed $5 \%$. Thus, only conditions satisfying this criterion are analyzed in the present work. Most of the tested operating conditions exhibit $\operatorname{COV}\left(I M E P_{\mathrm{n}}\right)<1 \%$. The range of investigated operating conditions is summarized in Table 4.

Table 4. Overview of the operating test conditions.

\begin{tabular}{|l|l|}
\hline Engine speed (rpm) & 1500 \\
\hline Intake temperature (K) & 323 \\
\hline Intake pressure (bar) & {$[0.6-1.2]$} \\
\hline $\mathrm{H}_{2}$ molar fraction in the fuel, $x_{\mathrm{H}_{2}}$ & {$[0.05-0.15]$} \\
\hline $\mathrm{H}_{2}$ energy fraction in the fuel & {$[0.038-0.12]$} \\
\hline $\mathrm{H}_{2}$ mass fraction in the fuel & {$[0.006-0.02]$} \\
\hline$\phi$ & {$[0.9-1.1]$} \\
\hline
\end{tabular}




\section{Calculation of the combustion efficiency}

Exhaust species measurement allows conducting an assessment on the combustion efficiency by looking at the ratio between exhaust and introduced species concentrations. In the present study, three efficiencies were calculated. The global combustion efficiency $\eta_{\mathrm{c}}$ follows the method of Heywood [27] and is a simple balance of the energy contained in the exhaust gases against the energy introduced:

$$
\eta_{\mathrm{c}}=1-\frac{n_{\mathrm{NH}_{3}, \mathrm{out}} \cdot L H V_{\mathrm{NH}_{3}}+n_{\mathrm{H}_{2}, \text { out }} \cdot L H V_{\mathrm{H}_{2}}}{n_{\mathrm{NH}_{3}, \text { in }} \cdot L H V_{\mathrm{NH}_{3}}+n_{\mathrm{H}_{2}, \mathrm{in}} \cdot L H V_{\mathrm{H}_{2}}}
$$

The two following quantities take the stoichiometry of the mixture into account by considering that excess air or excess fuel is not to be regarded as available for the combustion process. Thus, the fuel combustion efficiency $\eta_{\text {fuel }}$ is constructed as follows:

$$
\eta_{\text {fuel }}=1-\frac{E_{\mathrm{f}, \mathrm{out}}-E_{\mathrm{f}, \mathrm{out}}^{\text {excess }}}{E_{\mathrm{f}, \mathrm{in}}-E_{\mathrm{f}, \mathrm{in}}^{\text {excess }}}
$$

where $E_{\mathrm{f}}$ represents the energy contained in the fuel, calculated as previously in Eq. 3. This quantity allows focusing the analysis on the part of the fuel that is actually available for the combustion. Last, measurements of $\mathrm{O}_{2}$ exhaust concentrations are used to build the oxygen combustion efficiency $\eta_{\mathrm{O}_{2}}$ :

$$
\eta_{\mathrm{O}_{2}}=1-\frac{n_{\mathrm{O}_{2}, \text { out }}-n_{\mathrm{O}_{2}, \text { out }}^{\text {excess }}}{n_{\mathrm{O}_{2}, \text { in }}-n_{\mathrm{O}_{2}, \text { in }}^{\text {excess }}}
$$

That quantity is not directly related to energetic considerations, but provides additional information about the conversion of the reactants during the combustion.

\section{Results and Discussion}

\section{Engine Performance}

The optimization of the SI timing to obtain the maximum $I M E P_{\mathrm{n}}$ allowed successful engine operation for almost every intake pressure and mixture composition tested in this study. Only $\mathrm{NH}_{3} / \mathrm{H}_{2}$ mixtures with hydrogen contents as low as $5 \%$ did not ensure sufficient cyclic stability at $P_{\text {in }}=0.6$ bar. The SI timings used in the present study are shown in Figure 2 as a function of $P_{\text {in }}$ for various mixture compositions. Fig. 2a, 2b and $2 \mathrm{c}$ depict the SI timing for $\phi=0.9, \phi=$ 1.0 and $\phi=1.1$, respectively. The effect of the equivalence ratio on the optimal SI timing appears not significant near stoichiometry, due to similar flame propagation properties. Spark ignition closer to TDC is observed when the hydrogen content in the fuel is increased, as expected due to the increased flame speed with $\mathrm{H}_{2}$ addition. Increasing the intake pressure also leads to later SI timings, probably due to the improved thermodynamic conditions with increased cylinder load. It is interesting to note that the influence of the hydrogen enrichment on the optimal SI timing appears to be less significant when increasing $P_{\text {in }}$. Thus, it is to be expected that no or little $\mathrm{H}_{2}$ enrichment will be required for high load operation.

a)

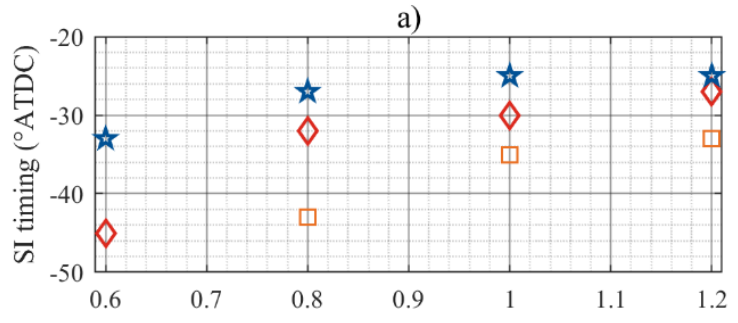

b)

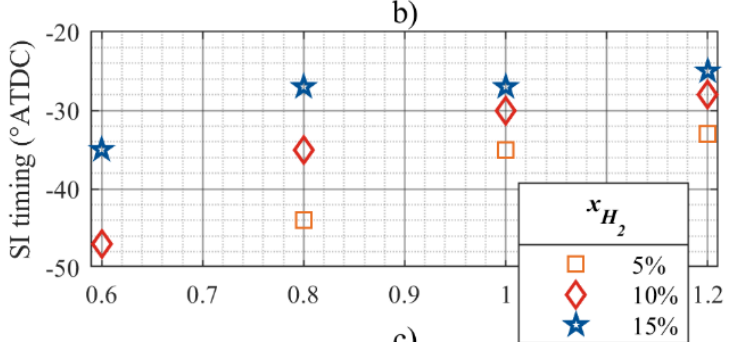

c)

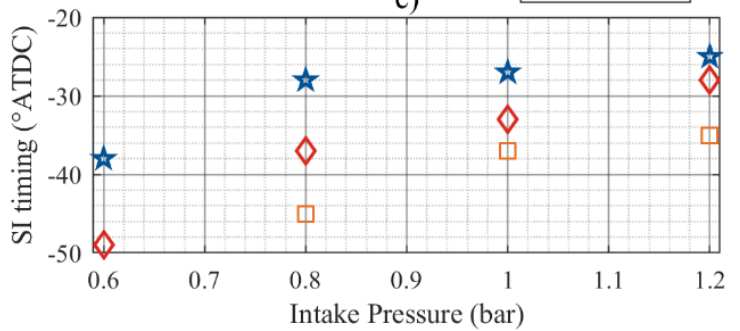

Figure 2. Optimized SI timing as a function of the intake pressure for various mixture compositions: a) $\phi=0.9$; b) $\phi=1.0$; c) $\phi=1.1$.

The averaged $I M E P_{\mathrm{n}}$ over 100 cycles is shown in Figure 3 for $x_{\mathrm{H}_{2}}=$ $5 \%$ (Fig. 3a) and $15 \%$ (Fig. 3b). . It is important to note here that the volumetric addition of hydrogen does not change much the energy content of the ammonia-based fuel/air mixtures. Indeed, the higher LHV by mass of $\mathrm{H}_{2}$ is compensated by its small molecular weight. $\mathrm{NH}_{3}$ thus exhibits a higher molar LHV than $\mathrm{H}_{2}$, which in turn is balanced by the greater air-fuel ratios required for ammonia combustion when compared to $\mathrm{H}_{2}$.Hence, the $I M E P_{\mathrm{n}}$ shows no significant change when $x_{\mathrm{H}_{2}}$ is varied. However, increasing the equivalence ratio from lean to stoichiometric and thus the fraction of fuel available for the combustion leads to an increased $I M E P_{\mathrm{n}}$. Further increase of $\phi$ above stoichiometry does not result in significant increase of the $I M E P_{\mathrm{n}}$ in most cases. Increasing the cylinder load logically results in an increased $I M E P_{\mathrm{n}}$, from 3.6 bar when $P_{\text {in }}=0.6$ bar to over 9 bar when $P_{\text {in }}=1.3$ bar at stoichiometry. The observed values demonstrate that part load operation of the engine is feasible, even at hydrogen enrichment levels as low as 0.6 $\% \mathrm{H}_{2}$ in the fuel by mass ( 5 vol.\%). Moreover, the power levels reached presently at elevated intake pressures are comparable with those obtained under fully loaded gasoline operation of the present engine (not plotted here). Therefore, this validates the interest of fueling such an engine with ammonia blends, especially under supercharged conditions, when considering the power output as a main driver. 


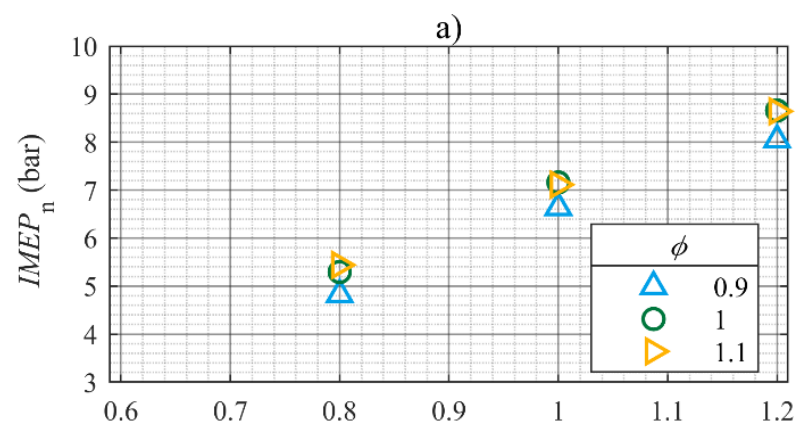

b)

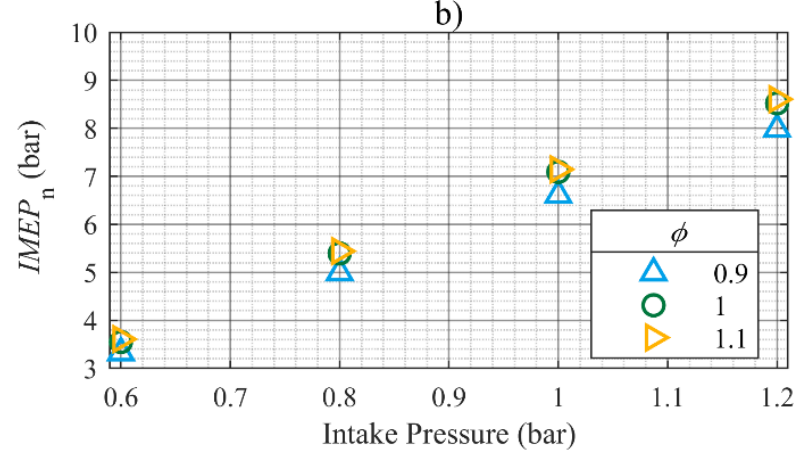

Figure 3. Net indicated mean effective pressure averaged over 100 cycles for a single cylinder. a) $x_{\mathrm{H}_{2}}=5 \%$; b) $x_{\mathrm{H}_{2}}=15 \%$.

In the interest of quantifying the efficiency of the power yield of the engine running on $\mathrm{NH}_{3} / \mathrm{H}_{2}$ fuel blends, the $I M E P_{\mathrm{n}}$ is compared with the energy introduced in the cylinder during one cycle (on a LHV basis) to give the indicated efficiency $\eta_{\text {ind }}$, shown in Figure 4 . The results suggest a beneficial influence of an increased intake pressure on the indicated efficiency, assumedly mainly due to the more favorable thermodynamic conditions at SI timing with increased load. The highest efficiencies are found for the near stoichiometric lean mixtures with $x_{\mathrm{H}_{2}} \leq 10 \%$, reaching $\eta_{\text {ind }}=37 \%$ at full load and exceeding that value beyond full load. Thus, it appears preferable to operate the engine slightly below stoichiometry and to keep hydrogen enrichment to a minimum.

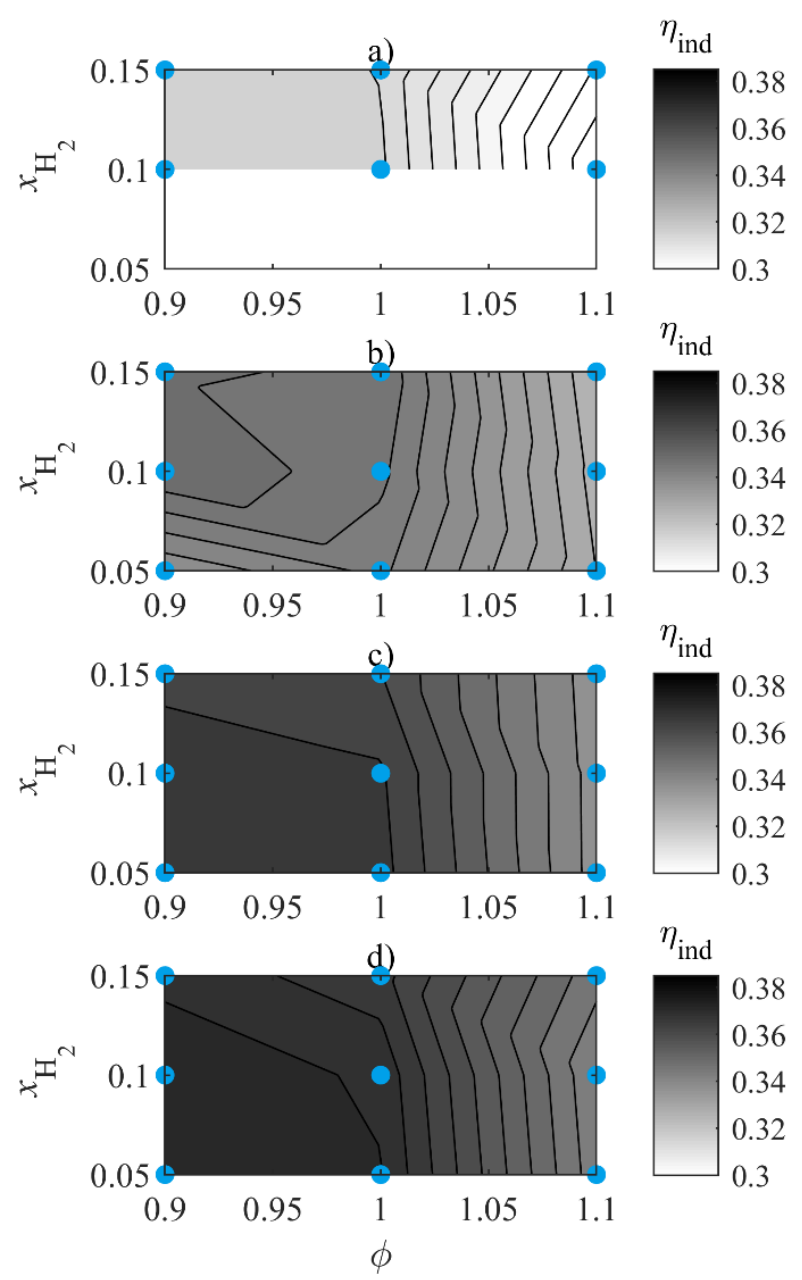

Figure 4. Indicated efficiency as function of the mixture composition for a) $P_{\text {in }}$ $=0.6$ bar, b) $P_{\text {in }}=0.8$ bar, c) $P_{\text {in }}=1.0$ bar and d) $P_{\text {in }}=1.2$ bar. Symbols: experimental points.

\section{Pollutant emissions}

All exhaust species concentrations are given in part per million by volume on a wet basis (ppmvw) in the present paper. Figure 5 shows the evolution of the $\mathrm{NOx}\left(\mathrm{NO}+\mathrm{NO}_{2}\right)$ exhaust concentrations with the various test conditions. NOx emissions decrease with increasing equivalence ratio as expected, due to the depletion of $\mathrm{O}_{2}$ in the reactive mixture. Increasing the presence of hydrogen in the fuel blend causes higher NOx emissions in most cases, assumedly due to higher flame temperatures. The increase of the intake pressure produces an increasing trend for the NOx emissions under lean conditions and a slightly decreasing trend under stoichiometric and rich conditions. The absolute NOx values observed in the present conditions are very high, up to more than 5000 ppmvw under lean conditions, and unacceptable without further mitigating measures. Operating under rich conditions with $\mathrm{H}_{2}$ enrichment kept at the minimum is more favorable regarding NOx emissions. 


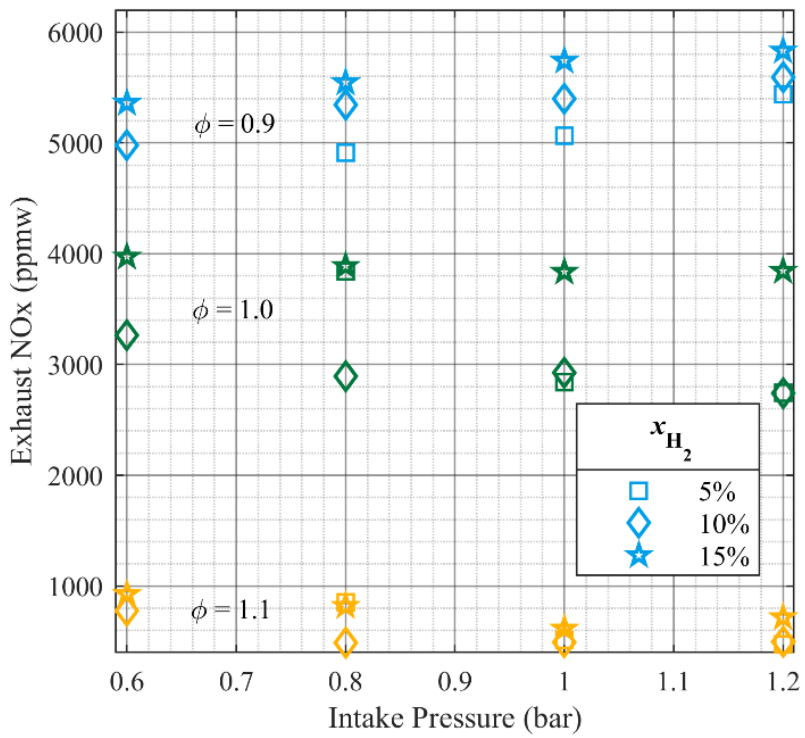

Figure 5. NOx emissions.

Operating an engine with an ammonia-based fuel brings the additional challenge of unburned $\mathrm{NH}_{3}$ slip, due to the poor combustion properties of ammonia. This is of essential matter since ammonia is toxic and is also a precursor of atmospheric compounds having a significant climate impact. $\mathrm{NH}_{3}$ exhaust concentrations measured during this study are shown in Figure 6. Hydrogen enrichment shows a beneficial effect by reducing significantly the emissions, proportionally more than it is substituted to $\mathrm{NH}_{3}$ in the fuel blend. Unsurprisingly, the highest $\mathrm{NH}_{3}$ emissions are found for rich mixtures, when excess fuel is present. The effect of the intake pressure appears relatively inconsistent and requires more investigations. The exhaust $\mathrm{NH}_{3}$ concentrations observed range from 8000 ppmvw under lean hydrogen-enriched conditions up to 18000 ppmvw (1.8 vol.\%) for rich conditions with low $\mathrm{H}_{2}$ content.
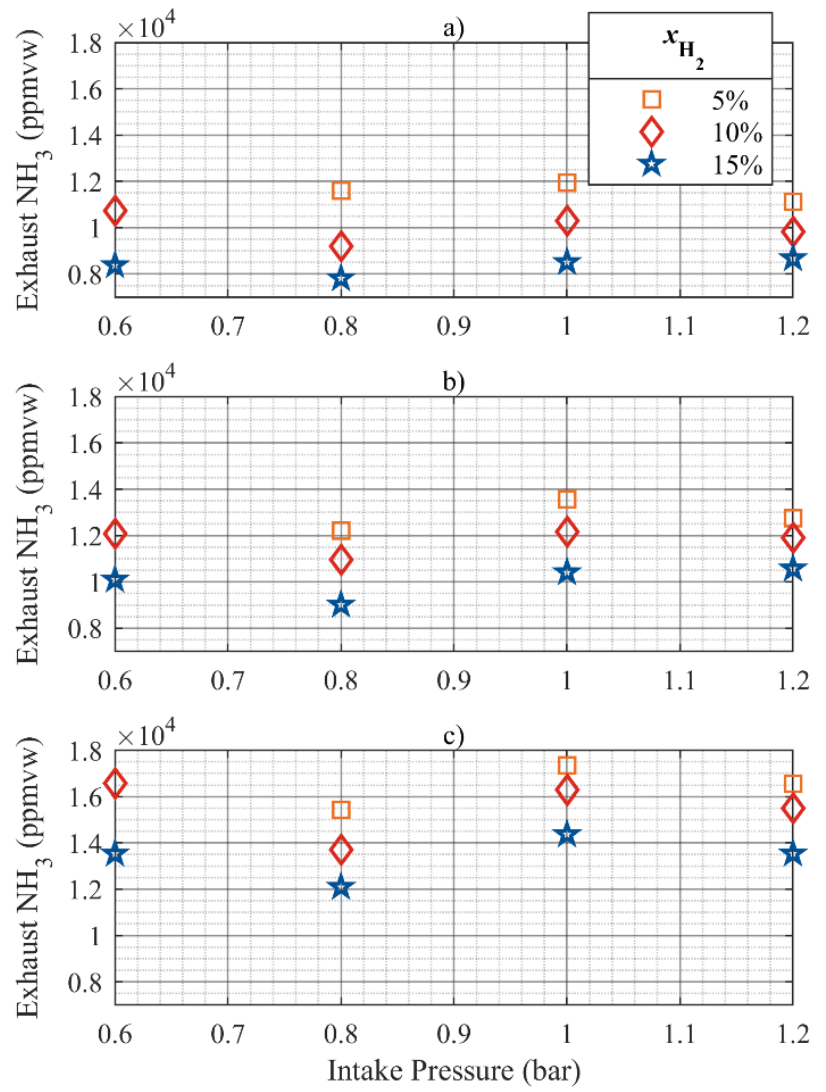

Figure 6. $\mathrm{NH}_{3}$ emissions. a) $\phi=0.9$; b) $\phi=1.0$; c) $\phi=1.1$.

It is thus of essential matter to reduce the pollutant emissions of the ammonia-fueled SI engine. However, this will be hardly doable by improving the mixture composition, since the $\mathrm{NH}_{3}$ and $\mathrm{NOx}$ emission trends are opposed when varying the latter, as illustrated in Figure 7. In the perspective of recombining $\mathrm{NH}_{3}$ and NOx using SCR or SNCR processes in the exhaust after-treatment system, such as Thermal DeNOx, that uses equal proportions of $\mathrm{NH}_{3}$ and $\mathrm{NO}$ in the presence of $\mathrm{O}_{2}$ and heat, the concentrations observed presently would not allow a total elimination of the pollutants. Partial recombination could be obtained for lean reactive mixtures if sufficient heat is provided.

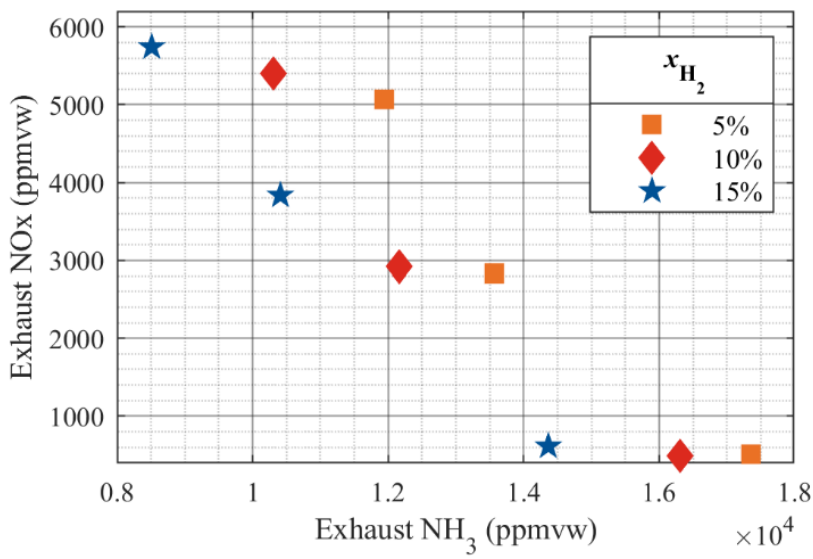

Figure 7. NOx emissions as a function of $\mathrm{NH}_{3}$ emissions at $P_{\text {in }}=1.0$ bar. 


\section{Combustion efficiency}

In order to link pollutant emissions with engine performance, a combustion efficiency analysis is presented in this section. To that purpose, exhaust $\mathrm{H}_{2}$ and $\mathrm{O}_{2}$ were measured in addition to unburned $\mathrm{NH}_{3}$. A comparison of $\mathrm{H}_{2}$ and $\mathrm{NH}_{3}$ exhaust concentrations is shown in Figure 8 for $\phi=1.1$. Measured values for lower equivalence ratios are below the accuracy of the $\mathrm{H}_{2}$ analyzer and are thus not depicted here. This is assumedly due to the total consumption of $\mathrm{H}_{2}$ in the presence of excess air, and consistent with the observations of Cornelius et al. [9]. The measurements in Fig. 8 show very similar values and trends for the concentrations of $\mathrm{H}_{2}$ and $\mathrm{NH}_{3}$. The very high $\mathrm{H}_{2}$ concentrations with respect to the intake proportions indicate $\mathrm{H}_{2}$ formation from $\mathrm{NH}_{3}$ dissociation during the combustion process. This is verified by comparing the measurements with a constructed value for the $\mathrm{H}_{2}$ concentration, obtained by assuming complete combustion as follows:

$$
\left[\mathrm{H}_{2}\right]^{\text {th }}=\left[\mathrm{H}_{2}\right]_{\text {out }}^{\text {excess }}+\frac{3}{2} \cdot\left(\left[\mathrm{NH}_{3}\right]_{\text {out }}^{\text {excess }}-\left[\mathrm{NH}_{3}\right]_{\text {out }}^{\text {measured }}\right)
$$

where the subscript "out" stands for concentrations in the exhaust gases. The factor $3 / 2$ comes from the stoichiometry of ammonia dissociation and is applied to the difference between the theoretical ammonia concentration that should be observed due to excess fuel injection assuming complete combustion, and the actual concentration that was measured in the exhaust gas. Thus, the assumption is made that all missing ammonia has been dissociated to $\mathrm{H}_{2}$ and $\mathrm{N}_{2}$ during the combustion process. The calculated values agree qualitatively with $\mathrm{H}_{2}$ measurements and quite quantitatively in the case $x_{\mathrm{H}_{2}}=15 \%$ (Fig. 8c). This suggest a combustion efficiency close to $100 \%$ in the latter case. The similar order of magnitude in the other cases provides first evidence for the hypothesis of ammonia dissociation. In the case of oxygen depletion presented in Fig. 8, that additional hydrogen remains unburned. Since the combustion is incomplete, additional quantities of unburned $\mathrm{H}_{2}$ and $\mathrm{NH}_{3}$ after dissociation should be added to $\left[\mathrm{H}_{2}\right]^{\text {th }}$ and may explain the discrepancies in Fig. 8a and 8b.
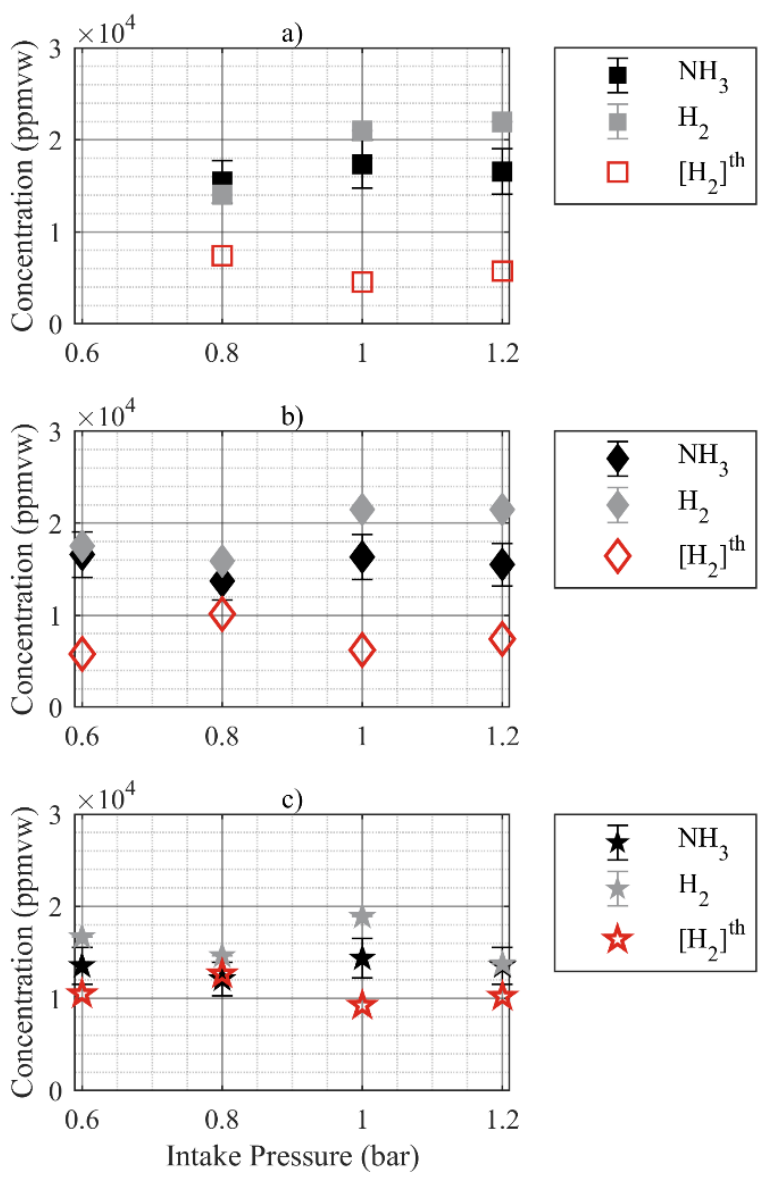

Figure 8. Comparison of $\mathrm{NH}_{3}$ and $\mathrm{H}_{2}$ concentrations in the exhaust for $\phi=$ 1.1. Filled symbols: measurements; hollow symbols: calculations. a) $x_{\mathrm{H}_{2}}=5$ $\%$; b) $x_{H_{2}}=10 \%$; c) $x_{H_{2}}=15 \%$.

In order to conduct a first evaluation of the combustion completeness, a combustion efficiency assessment was done by combining different calculation methods based on unburned fuel species and $\mathrm{O}_{2}$ measurements according to Eqs. 3-5. The fuel combustion efficiency $\eta_{\text {fuel }}$ as calculated with Eq. 4 is shown in Figure 9a for a representative case. It should be noted that the excess fuel energy in the sense of stoichiometry is not considered as available energy in the calculation of this quantity. The results indicate that more than $93 \%$ of the available energy content of the fuel is consumed by the combustion in the worst case, reaching $97 \%$ and more in the best cases. In spite of significant uncertainties due to the accuracy of the gas analysis methods, increasing the $\mathrm{H}_{2}$ content in the fuel blend seems to improve the efficiency of the energy conversion by the combustion. However, it does not seem to improve $\mathrm{O}_{2}$ conversion as shown in Figure 9b, with the oxygen combustion efficiency $\eta_{\mathrm{O}_{2}}$ calculated with Eq. 5. The equivalence ratio influences the combustion efficiency as lowest values are observed for $\phi=1.0$ and highest values for $\phi=1.1$ both for the fuel and oxygen-based quantities. 

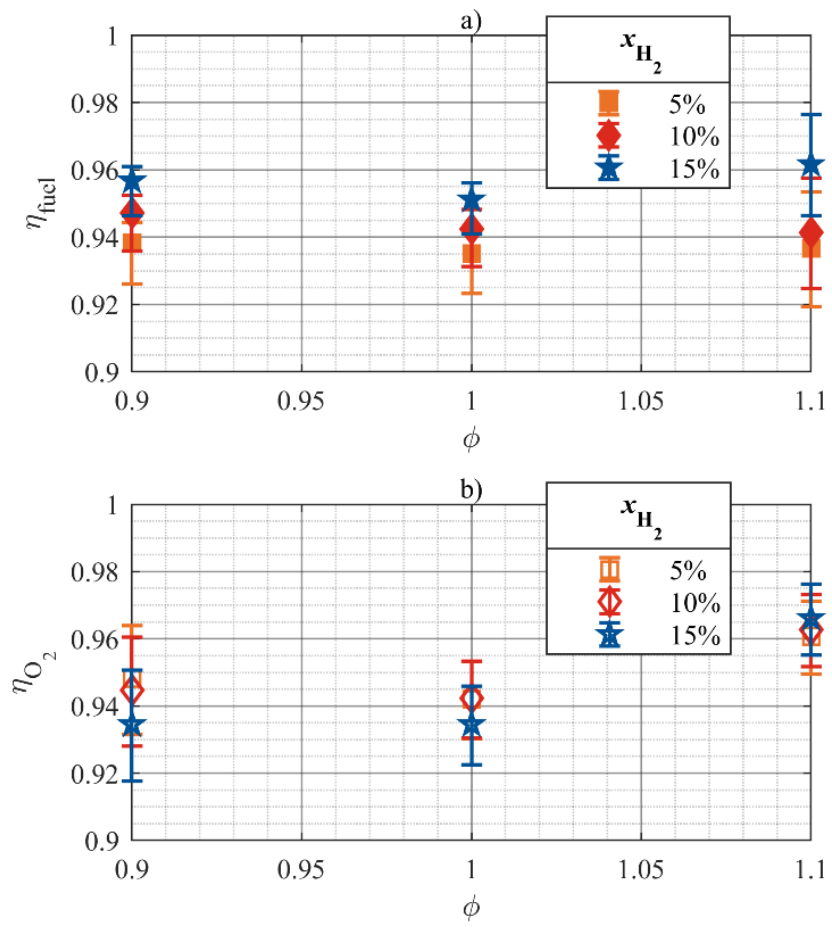

Figure 9. Combustion efficiencies for $P_{\text {in }}=1.0$ bar based on: a) a LHV balance on unburned fuel species measurements and b) a balance on $\mathrm{O}_{2}$ exhaust measurements.

Figure 10 eventually shows the combustion efficiency $\eta_{c}$ calculated as a LHV-weighted ratio of exhaust fuel quantity against intake fuel quantity with no regard on the amount of fuel actually able to burn (as a function of the equivalence ratio) as in Eq. 3. This is the classical definition of the combustion efficiency as in [27]. It provides valuable information on the global energy balance between the energy contained in the injected fuel and the energy actually released by the combustion and thus available to furnish work. The results show that the injected energy is most efficiently used below stoichiometry for hydrogen-enriched mixtures. This is expected, since the presence of excess fuel leads to systematic losses under rich conditions. The influence of the intake pressure is not consistent and appears to have little relevance in the present conditions.

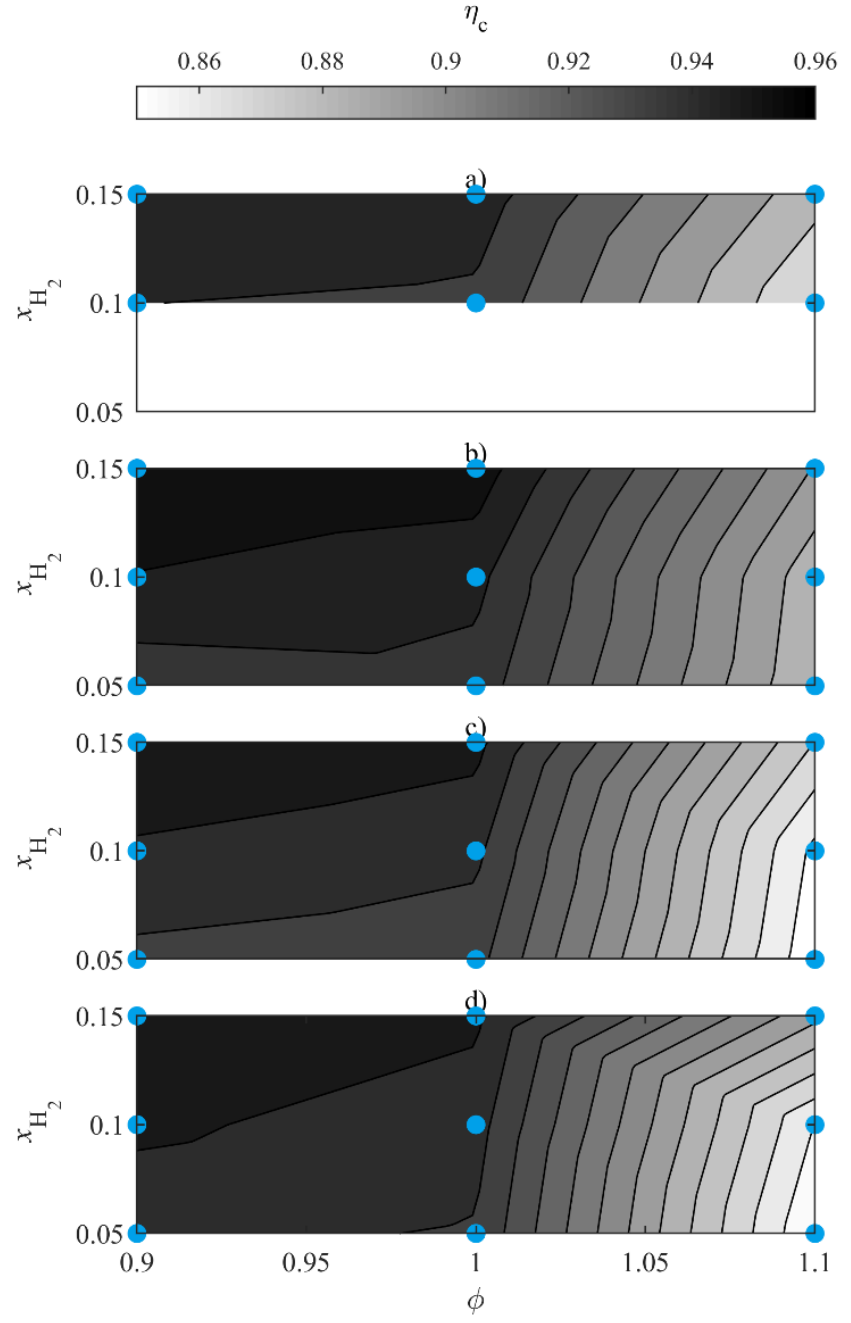

Figure 10. Global combustion efficiency. a) $P_{\text {in }}=0.6$ bar, $P_{\text {in }}=0.8$ bar, b) $P_{\text {in }}=$ 1.0 bar and c) $P_{\text {in }}=1.2$ bar. Symbols: experimental conditions.

\section{Summary and Conclusions}

As ammonia is gaining increased interest as a sustainable fuel and has been validated as a suitable fuel for internal combustion engines, it is worthwhile to investigate the characteristics of a recent SI engine fueled with ammonia. Objectives are to assess the best operating conditions in the current configuration, propose optimization strategies and provide useful data for comparisons and validation purposes.

In the present study, experiments were conducted in a recent PSA spark-ignition engine used as a single-cylinder engine fueled with premixed ammonia/hydrogen/air mixtures at a constant speed of 1500 $\mathrm{rpm}$. The parameters were the intake pressure, the fuel/air equivalence ratio and the hydrogen fraction in the fuel that was varied between 5 and $15 \%$ by volume. The spark timing was set at MBT and the compression ratio was 10.5:1.

The results confirm and extend observations that were made in previous SI engine studies. The engine can be operated with very low cyclic variability from part load to supercharged operation, even at very low hydrogen fractions in the fuel, provided that the sparkignition timing is correctly advanced. Increasing the cylinder load is found to be a good strategy to increase the power output, allowing to reach levels under supercharged conditions that are comparable with full load gasoline operation. Supercharging the engine also improves the indicated efficiency that reaches maximum values higher than $37 \%$ under lean conditions for volumetric hydrogen fractions smaller 
than $10 \%$. Under lean conditions, very high NOx emissions up to 6000 ppmvw are found, with exacerbating effects of increased hydrogen fraction and intake pressure. NOx emissions decrease when the mixtures become richer down to less than 1000 ppmvw. Unburned $\mathrm{NH}_{3}$ emissions are found in the order of magnitude of $1 \%$ by volume and up to $1.8 \%$ under rich conditions. Unburned $\mathrm{H}_{2}$ emissions are also found in rich conditions in the same order of magnitude. Hydrogen enrichment of the fuel improves the combustion efficiency and leads to reduced unburned emissions. The global fuel efficiency is maximum under lean conditions, but the fraction of the fuel actually able to burn (with respect to available oxygen) does it more efficiently under rich conditions.

The main conclusions are as follows:

1. Hydrogen-enriched ammonia is a suitable fuel for modern SI engines, even in part-load operation.

2. Supercharged operation is recommended when possible to improve the indicated efficiency and power output.

3. The best hydrogen fraction in the fuel results from a tradeoff between indicated efficiency, NOx emissions and combustion efficiency. With the current engine design and speed a good tradeoff seems to be around $10 \mathrm{vol} . \% \mathrm{H}_{2}$, guaranteeing a good combustion efficiency associated with moderate $\mathrm{NH}_{3}$ emissions, as well as moderate flame temperatures, ensuring moderate NOx emissions and a satisfactory indicated efficiency.

4. Near-stoichiometric lean operation is recommended, since it provides satisfactory power output and efficiencies, while mitigating both $\mathrm{NOx}$ and $\mathrm{NH}_{3}$ emissions, keeping them in the same order of magnitude in the perspective of dedicated aftertreatment systems. However, slightly rich operation with exhaust gas recirculation might be of interest, due to the presence of significant quantities of unburned $\mathrm{H}_{2}$ in the exhaust gas, and will be investigated in the future.

5. The issue of pollutant emissions remains the major challenge of ammonia combustion in spark-ignition engines, calling for further research and development on combustion and pollutant formation models, as well as dedicated engineering solutions, such as SCR or SNCR after-treatment systems.

\section{References}

[1] UNFCCC, Paris Agreement, 2015.

[2] Zamfirescu, C., Dincer, I., "Using ammonia as a sustainable fuel", J. Power Sources. 185: 459-465, 2008, doi: 10.1016/j.jpowsour.2008.02.097.

[3] Zamfirescu, C., Dincer, I., "Ammonia as a green fuel and hydrogen source for vehicular applications", Fuel Process. Technol. 90: 729-737, 2009, doi: 10.1016/j.fuproc.2009.02.004

[4] Bicer, Y., Dincer, I., "Life cycle assessment of ammonia utilization in city transportation and power generation", $J$. Clean. Prod. 170: 1594-160, 2018, doi: 10.1016/j.jclepro.2017.09.243.

[5] Linstrom, P.J., Mallard, W.G., NIST Chemistry WebBook, NIST Standard Reference Database Number 69, National Institute of Standards and Technology, accessed June 2019.

[6] Mørch, C.S., Bjerre, A., Gøttrup, M.P., Sorenson, S.C., Schramm, J., "Ammonia/hydrogen mixtures in an SI-engine: Engine performance and analysis of a proposed fuel system", Fuel. 90: 854-864, 2011, doi: 10.1016/j.fuel.2010.09.042.

[7] Valera-Medina, A., Xiao, H., Owen-Jones, M., David, W.I.F., Bowen, P.J., "Ammonia for power", Prog. Energy Combust. Sci. 69: 63-102, 2018, doi: 10.1016/j.pecs.2018.07.001.

[8] Gray, J.T.J., Dimitroff, E., Meckel, N.T., Quillian, R.D.J., "Ammonia Fuel - Engine Compatibility and Combustion",
SAE Technical Paper 660156, 1966, doi: 10.4271/660156.

[9] Cornelius, W., Huellmantel, L.W., Mitchell, H.R.,

"Ammonia as an engine fuel", SAE Technical Paper 650052, 1965, doi: $10.4271 / 650052$.

[10] Sawyer, R.F., Starkman, E.S., Muzio, L., Schmidt, W.L., "Oxides of Nitrogen in the Combustion Products of an Ammonia Fueled Reciprocating Engine", SAE Technical Paper 680401, 1968, doi: 10.4271/680401.

[11] Starkman, E.S., Newhall, H.K., Sutton, R., Maguire, T., Farbar, L., "Ammonia as a Spark Ignition Engine Fuel: Theory and Application", SAE Technical Paper 660155, 1966, doi: $10.4271 / 660155$.

[12] Reiter, A.J., Kong, S.C., "Demonstration of compressionignition engine combustion using ammonia in reducing greenhouse gas emissions", Energy and Fuels. 22: 29632971, 2008, doi: 10.1021/ef800140f.

[13] Reiter, A.J., Kong, S.C., "Combustion and emissions characteristics of compression-ignition engine using dual ammonia-diesel fuel", Fuel. 90: 87-97, 2011, doi: 10.1016/j.fuel.2010.07.055.

[14] Gill, S.S., Chatha, G.S., Tsolakis, A., Golunski, S.E., York, A.P.E., "Assessing the effects of partially decarbonising a diesel engine by co-fuelling with dissociated ammonia", Int. J. Hydrogen Energy. 37: 6074-6083, 2012, doi: 10.1016/j.ijhydene.2011.12.137.

[15] Gross, C.W., Kong, S.C., "Performance characteristics of a compression-ignition engine using direct-injection ammonia-DME mixtures", Fuel. 103: 1069-1079, 2013, doi: 10.1016/j.fuel.2012.08.026.

[16] Ryu, K., Zacharakis-Jutz, G.E., Kong, S.-C., "Performance characteristics of compression-ignition engine using high concentration of ammonia mixed with dimethyl ether", Appl. Energy. 113: 488-499, 2014, doi: 10.1016/j.apenergy.2013.07.065.

[17] Pochet, M., Truedsson, I., Foucher, F., Jeanmart, H., Contino, F., "Ammonia-Hydrogen blends in HomogeneousCharge Compression-Ignition Engine", SAE Technical Paper 2017-24-0087, 2017, doi: 10.4271/2017-24-0087. Grannell, S.M., Assanis, D.N., Bohac, S. V., Gillespie, D.E., "The Fuel Mix Limits and Efficiency of a Stoichiometric, Ammonia, and Gasoline Dual Fueled Spark Ignition Engine", J. Eng. Gas Turbines Power. 130: 042802, 2008, doi: $10.1115 / 1.2898837$.

[19] Grannell, S.M., Assanis, D.N., Gillespie, D.E., Bohac, S. V, "Exhaust Emissions From a Stoichiometric, Ammonia and Gasoline Dual Fueled Spark Ignition Engine", Proc. ASME Intern. Combust. Engine Div., paper ICES2009-76131, 2009, doi: 10.1115/ICES2009-76131.

[20] Ryu, K., Zacharakis-Jutz, G.E., Kong, S.-C., "Effects of gaseous ammonia direct injection on performance characteristics of a spark-ignition engine", Appl. Energy. 116: 206-215, 2014, doi: 10.1016/j.apenergy.2013.11.067.

[21] Ryu, K., Zacharakis-Jutz, G.E., Kong, S.C., "Performance enhancement of ammonia-fueled engine by using dissociation catalyst for hydrogen generation", Int. J. Hydrogen Energy. 39: 2390-2398, 2014, doi: 10.1016/j.ijhydene.2013.11.098.

[22] Frigo, S., Gentili, R., Doveri, N., "Ammonia Plus Hydrogen as Fuel in a S.I. Engine: Experimental Results", SAE Technical Paper 2012-32-0019, 2012, doi: 10.4271/2012-32$\underline{0019}$.

[23] Pozzana, G., Bonfanti, N., Frigo, S., Doveri, N., Dario, P., Mattoli, V. et al., "A Hybrid Vehicle Powered by Hydrogen and Ammonia", SAE Technical Paper 2012-32-0085, 2012, doi: $10.4271 / 2012-32-0085$.

[24] Frigo, S., Gentili, R., "Analysis of the behaviour of a 4stroke Si engine fuelled with ammonia and hydrogen", Int. J. Hydrogen Energy. 38: 1607-1615, 2013, doi: 10.1016/j.ijhydene.2012.10.114. 
[25] Comotti, M., Frigo, S., "Hydrogen generation system for ammonia-hydrogen fuelled internal combustion engines", Int. J. Hydrogen Energy. 40: 10673-10686, 2015, doi: 10.1016/j.ijhydene.2015.06.080.

[26] Westlye, F.R., Ivarsson, A., Schramm, J., "Experimental investigation of nitrogen based emissions from an ammonia fueled SI-engine", Fuel. 111: 239-247, 2013, doi: 10.1016/j.fuel.2013.03.055.

[27] Heywood, J.B., "Internal Combustion Engine Fundamentals", 1988, ISBN: 0-07-100499-8.

\section{Contact Information}

Charles LHUILLIER

Laboratoire PRISME

Université d'Orléans (France)

charles.lhuillier@univ-orleans.fr

\section{Acknowledgement}

The research leading to these results has received funding from the French Government's "Investissement d'Avenir" program: "Laboratoire d'Excellence CAPRYSSES" (Grant No ANR-11LABX-0006-01).

\section{Abbreviations}

${ }^{\circ}$ ATDC

BSEC

CAD

CFR

CI

COV

CR

FL

FTIR

GDI

GT

ICE

$I M E P_{\mathrm{n}}$

LBV

LHV

MBT

NOx ppmvw

rpm

SCR

SI

SNCR

TDC part per million by volume on a wet basis

revolutions per minute

Selective Catalytic Reduction

Spark-ignition

Selective Non Catalytic Reduction

Top Dead Center

crank angle degree After Top Dead

Center

Brake Specific Energy Consumption

Crank Angle Degree

Collaborative Fuel Research engine

Compression-Ignition

Coefficient of Variation

Compression Ratio

Flammability Limits

Fourier Transform InfraRed gas analyzer

Gasoline Direct Injection

Gas turbine

Internal Combustion Engine

net Indicated Mean Effective Power

Laminar Burning Velocity

Lower Heating Value

Maximum Brake Torque

Nitrogen Oxides ( $\mathrm{NO}$ and $\mathrm{NO}_{2}$ ) 